\title{
CONTAMINAÇÃO DA ÁGUA SUBTERRÂNEA POR NITRATO NO PARQUE ECOLOGICO DO TIETÊ - SÃO PAULO, BRASIL
}

\author{
Claudia Varnier, Ricardo Hirata*
}

\begin{abstract}
The aim of this study is to investigate groundwater contamination caused by septic tank, which infiltrates domestic effluent into a sandy-alluvial unconfined aquifer at Parque Ecológico do Tietê (São Paulo, Brasil).

The methodology used is based on chemical analysis of 68 shallow monitoring wells (up to 5.0 deep) installed at $50 \times 50 \mathrm{~m}$ area. Some chemical parameters as nitrate, nitrite, ammonium, chloride, $\mathrm{pH}$, Eh, electric conductivity and dissolved oxygen have been measured fortnightly using portable equipaments. Major ions and nitrogen compounds (organic- $\mathrm{N}$, ammonia, ammonium, nitrite, nitrate) have been analysed monthly.

This detailed monitoring program has allowed to identify three different geochemical zones, according to predominance of nitrogen species: organic- $\mathrm{N}$, ammonium and nitrate. Following the groundwater flux, it is also possible to verify a decrease in the $\mathrm{pH}$ values. From chloride concentration variation and eletric conductivity, the dispersion of the plume was calculated. Fast contaminant concentration variations have been attributed to the rapid aquifer recharge that provokes deformation into the streamtubes geometry.
\end{abstract}

Palavras chave: Nitrato, Tanque séptico, Água subterrânea.

\section{INTRODUÇÃO}

O nitrato é o poluente de ocorrência mais freqüente nas águas subterrâneas. Em concentrações superiores a $10 \mathrm{mg} / \mathrm{L} \quad \mathrm{NO}_{3}^{-}-\mathrm{N}$, pode causar metahemoglobinemia e câncer. Além do uso de fertilizantes agrícolas e criação de animais, os sistemas de saneamento in situ, quer por tanques sépticos ou fossas rudimentares,

\footnotetext{
* Departamento de Geologia Sedimentar e Ambiental - Instituto de Geociências, Universidade de São Paulo. Rua do Lago, 562 - Cidade Universitária, CEP 05508-900, São Paulo (SP), Brasil. E-mails: clvarnier@hotmail.com e rhirata@usp.br. Tel: (5511) 3818-4804/3818-4230. FAX (5511) 3818-4207.
} 
constituem outra importante fonte de nitrato nas águas subterrâneas.

Segundo dados fornecidos pelo IBGE (1991), 42\% da população brasileira (aproximadamente 61 milhões de pessoas) utiliza fossas rudimentares ou não possui qualquer sistema de saneamento que, na prática, se traduz na deposição inadequada dos efluentes líquidos, muitas vezes diretamente no aqüífero (fossas negras escavadas até o nível freático). Uma agravante a este problema são as favelas, dada à grande densidade populacional e alta concentração de fossas negras, muito próximas aos poços cacimbas.

O problema da interrelação fossapoço não se restringe apenas às áreas faveladas. Segundo o mesmo censo, 20\% da população do País utiliza poços próprios para seu abastecimento e somente $\quad 32 \%$ está conectada devidamente à rede de esgoto.

Embora os estudos do
comportamento e atenuação de nutrientes (nitrogênio e fósforo) já datem alguns anos (Robertson et al., 1991; Wilhelm et al., 1994; Hirata et al., 1996; Rudolph et al., 1997), trabalhos específicos a respeito da contaminação de aqüíferos por nitrogênio, com programa de monitoramento freqüente, são raros no País, sobretudo quando o tema é enfocado com alto grau de detalhe.
Esse trabalho tem como objetivo principal a caracterização da contaminação das águas subterrâneas causada por uma fossa séptica, acompanhando a hidrogeoquímica do nitrogênio, através de 68 poços de monitoramento instalados numa área de $2.500 \mathrm{~m}^{2}$.

\section{ÁREA DE ESTUDO}

A área de estudo localiza-se nas dependências do Parque Ecológico Tietê-Engenheiro Goulart (PET-EG), zona leste do município de São Paulo (Figura 1). O PET-EG foi criado em 1976, com a finalidade de preservar as várzeas do Rio Tietê e combater, juntamente com outras obras (barragens, retificação do rio, desassoreamento), as enchentes na Região Metropolitana da Grande São Paulo.

O Casarão, atual Museu do Tietê, era a antiga residência do proprietário do sítio que existia na área, antes da inauguração do PET-EG. O prédio de dois pavimentos possui quatro banheiros e, conectado a este sistema, está também o refeitório dos trabalhadores. Todo o esgoto proveniente destas duas edificações é drenado para um sistema de tanque séptico. Este sistema consiste de dois tanques de concreto com dimensões de $1,5 \mathrm{~m}$ de diâmetro por $1 \mathrm{~m}$ de profundidade e nunca foram limpos 
desde a criação do PET. O primeiro tanque permite a infiltração do líquido no tanque recebe o efluente in natura e o solo, através de aberturas em sua transfere para o segundo, através de parede lateral. Os fundos dos dois tubo na sua porção superior. O segundo tanques são fechados.
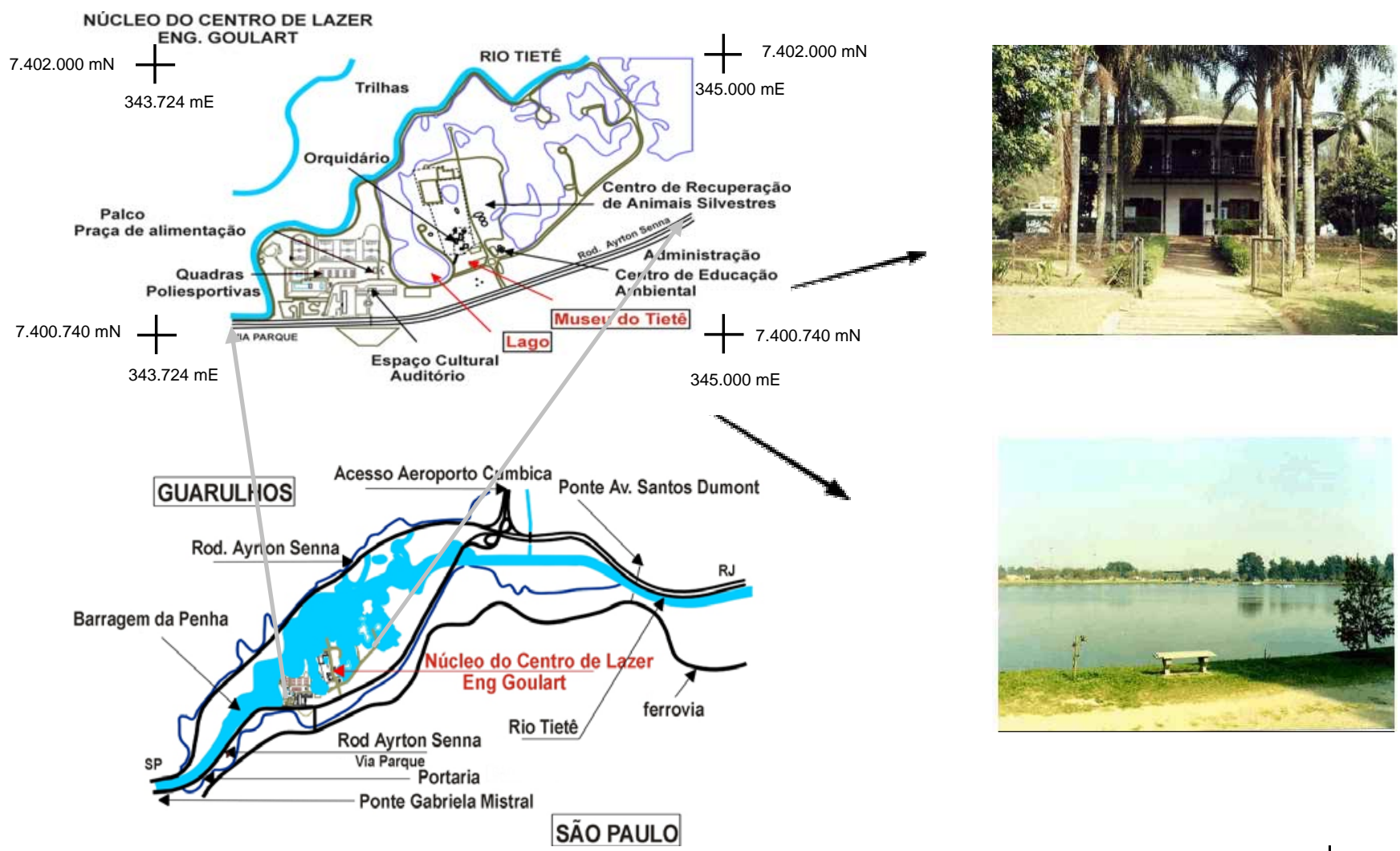

Figura 1 - Localização da área de estudo.

\section{HIDROGEOLOGIA}

O Casarão e as edificações que compõe a área de estudos estão situados na planície do Rio Tietê. Esta área de $2.500 \mathrm{~m}^{2}$ é bastante plana e as diferenças de topografia não são maiores que $0,76 \mathrm{~m}$. Na área ocorre um aqüífero do tipo livre, com valores de condutividade hidráulica horizontal entre $1,5 \times 10^{-7}$ a $6,8 \times 10^{-5} \mathrm{~m} / \mathrm{s}$.

O aqüífero de porosidade primária está associado aos sedimentos quaternários do aluvião do Rio Tietê, apresentando uma espessura média de $20 \mathrm{~m}$, conforme três sondagens do tipo SPT perfuradas na área. Sob este material encontram-se sedimentos terciários conectados hidraulicamente e correlacionáveis à Bacia de São Paulo. A espessura média dos sedimentos na área é maior que $100 \mathrm{~m}$, como atesta um poço tubular perfurado junto ao Casarão.

Os 68 poços de monitoramento com até 5,0m de profundidade 
atravessam as coberturas aluviais quaternárias representadas por lentes de argila, silte e areia intercaladas, de cor marrom claro a escuro e riqueza de material orgânico no primeiro 0,5m. Após 2,0m, observam-se areias finas não consolidadas de cor parda e amarela, mais permeáveis. O material perfurado não mostrou camadas com características de confinamento.

A recarga deste aqüífero ocorre em toda a sua zona aflorante e a descarga junto às drenagens superficiais e lagos. Esta recarga é mais pronunciada nos meses úmidos (dezembro a março). Através do levantamento topográfico de todos os poços e medições periódicas dos níveis estáticos, foram confeccionados mapas potenciométricos mensais. Estes mapas mostram duas direções principais de fluxo na área: uma a norte, em direção ao Rio Tietê, e outra a noroeste. O sistema séptico, considerado como ponto de maior carga hidráulica da área, propicia uma distribuição radial das equipotenciais a partir do centro deste (Figura 2).

A distribuição das equipotenciais apresenta uma complexidade com formação de "ilhas" tanto de maior como de menor valor de carga hidráulica que mudam com o tempo. Isto indica que além das direções gerais do fluxo da água subterrânea serem a NW e $\mathrm{N}$ da área, podem ser notadas pequenas mudanças locais nas direções de fluxo.

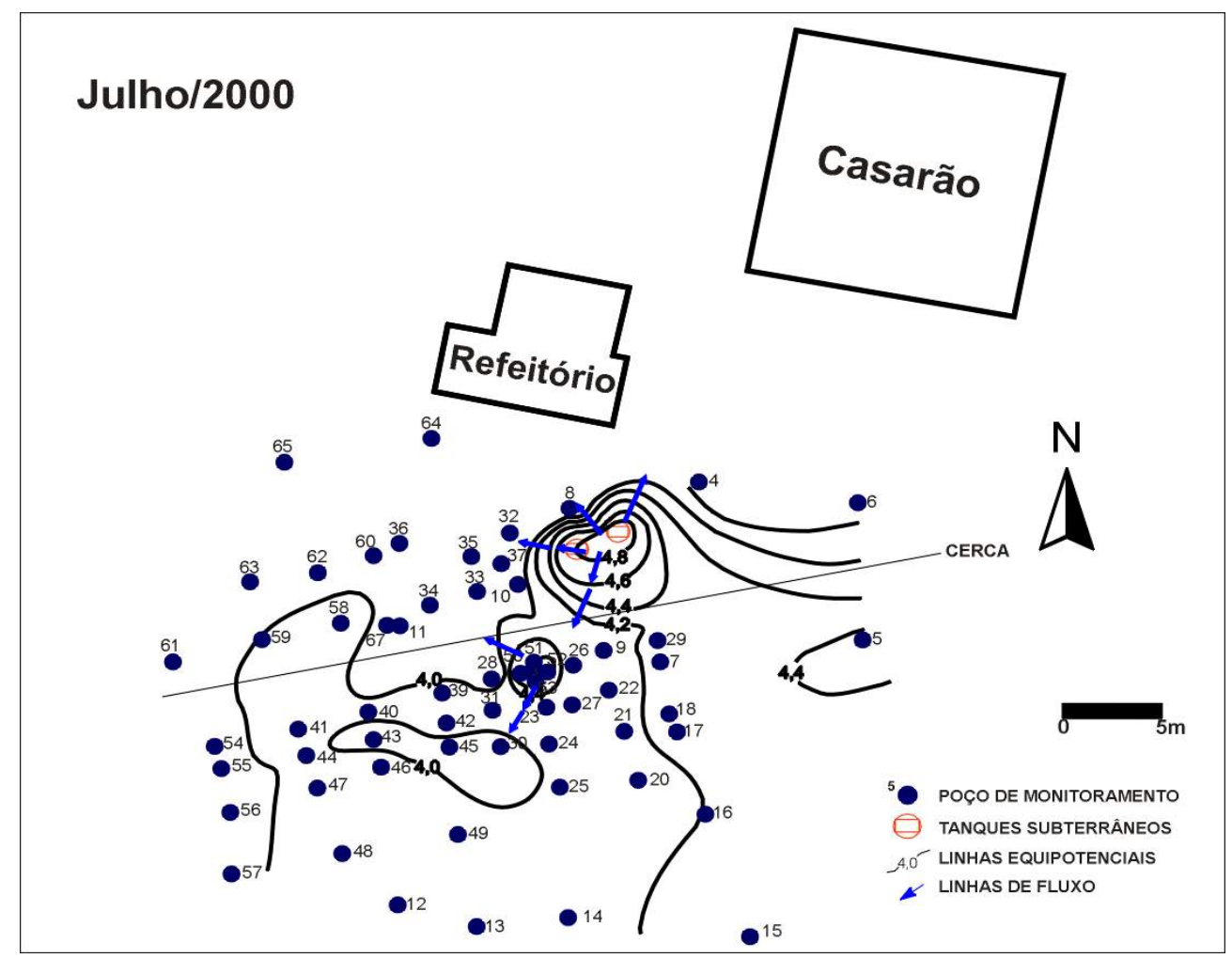

Figura 2 - Mapa potenciométrico referente ao mês de julho de 2000. 
COLETA DE AMOSTRAS

A perfuração dos poços de monitoramento foi executada através de trado manual de $100 \mathrm{~mm}$ de diâmetro acoplado a um sistema de haste com até $5 \mathrm{~m}$ de comprimento. Nesses furos foram instalados piezômetros constituídos de tubos de PVC, onde o último $0,5 \mathrm{~m}$ foi furado e encoberto com telas de bidim. O espaço anular entre o tubo e o furo foi preenchido com cascalho (pré-filtro tipo pérola) até cobrir a seção filtrante e acima deste, um selo de bentonita. O restante do espaço foi preenchido com o material da escavação. Em volta da boca do poço foi construída uma laje de proteção com tampa metálica fechada com cadeado.

Anterior à todas as amostragens, efetuou-se a limpeza dos poços de monitoramento com o seu esgotamento através de bombeamento intensivo segundo as normas da USEPA (apud Foster \& Gomes, 1989). A amostragem da água subterrânea nos poços foi feita através de uma bomba peristáltica da marca Geopump.

As amostras coletadas foram filtradas através de uma bomba a vácuo manual da marca Nalgene e acondicionadas em frascos de polietileno, conservadas em geladeira de plástico a $4^{\circ} \mathrm{C}$ e encaminhadas ao laboratório para análise química.

Alguns parâmetros químicos foram medidos quinzenalmente em campo com o uso de equipamentos como o RqflexPlus (nitrato, nitrito, amônio) e Microquant (cloreto), ambos da MERCK. Os métodos utilizados por estes equipamentos foram respectivamente a reflectometria e colorimetria. Além destas espécies químicas foram também medidos com a mesma freqüência, o nível estático, pH, Eh, condutividade elétrica, temperatura da água e oxigênio dissolvido através de equipamentos da marca WTW.

Foram também efetuadas análises mensais em laboratório, para uma melhor caracterização da pluma contaminante no tempo e espaço. Dois grupos de parâmetros foram analisados segundo a conveniência e necessidade. O primeiro incluía os compostos nitrogenados (nitrogênio total, nitrogênio orgânico, amônia, nitrito, nitrato) e o segundo, além destes compostos, os íons maiores (cálcio, ferro, magnésio, potássio, sódio, sulfato e cloreto). Estas análises foram feitas no laboratório CEIMIC em São Paulo. Os procedimentos de preservação da amostra e metodologias analíticas adotados obedeceram os critérios adotados pela APHA (1995) e USEPA (2001). 


\section{RESULTADOS OBTIDOS}

A variação no comportamento de diversos parâmetros físico-químicos e do nível estático foi observada no período de novembro de 1998 a abril de 2000, através de 25 etapas de campo.

Durante os meses de estiagem (abril a agosto) foram notados os maiores valores de níveis estáticos (águas mais profundas), com recuperação nos meses mais chuvosos (setembro a março). O valor médio durante a estiagem foi de $2,16 \mathrm{~m}$ e durante as chuvas, $1,71 \mathrm{~m}$.

Independente das flutuações sazonais que fazem com que o nível médio do aqüífero freático se eleve, existem variações rápidas, em intervalos menores que um mês, devido às chuvas diárias ou semanais. Estas flutuações foram de até $0,93 \mathrm{~m}$ em menos de 15 dias no poço PET 9 durante a estiagem, sendo mais acentuadas na estação chuvosa, com uma variação de até 1,37m, como constatado no poço PET 6, em menos de uma semana de chuvas.

Existe, portanto, uma rápida resposta do aqüífero para eventos de chuva. A região onde se realiza o estudo apresenta um conjunto de características propícias a uma recarga com grande aproveitamento da precipitação local que são: área plana, onde o escoamento superficial é bastante reduzido; solos bastante ricos em matéria orgânica e sombreada por árvores, que mantém alta a umidade do solo durante o ano, e níveis estáticos não muito profundos.

Quanto aos íons da série nitrogenada, observa-se uma predominância dos compostos menos oxidados como nitrogênio orgânico e amônio próximos ao sistema séptico, a uma distância de $7 m$, uma vez que estes são estáveis em condições redutoras. A medida em que se afasta da fonte, ocorre uma diminuição na concentração destas espécies e aumento gradativo na concentração relativa de nitrato (Figura 3).

$\mathrm{Na}$ proximidade da fossa, o ambiente redutor é mantido pelo rápido consumo de oxigênio a partir da degradação de matéria orgânica. Compostos mais oxidados aparecem quando o carbono é degradado e pelo contato com águas mais ricas em oxigênio.

As concentrações de cloreto, conforme o esperado, foram maiores nos poços situados próximos à fossa, reduzindo-se com o distanciamento. Através dos resultados obtidos (Figura 3), observa-se que a concentração de cloreto no PET37 é de $62,0 \mathrm{mg} / \mathrm{L}$ e no PET11 é de 11,8mg/L. Comparando estes valores observa-se que esta espécie sofre uma diminuição de $81 \%$ na sua concentração. Sendo o cloreto um íon conservativo, esta redução é 
atribuída aos processos de dispersão hidráulica. O mesmo não acontece para a série nitrogenada onde o nitrogênio orgânico, por exemplo, sofreu uma decréscimo de $98 \%$ na sua oxidados.

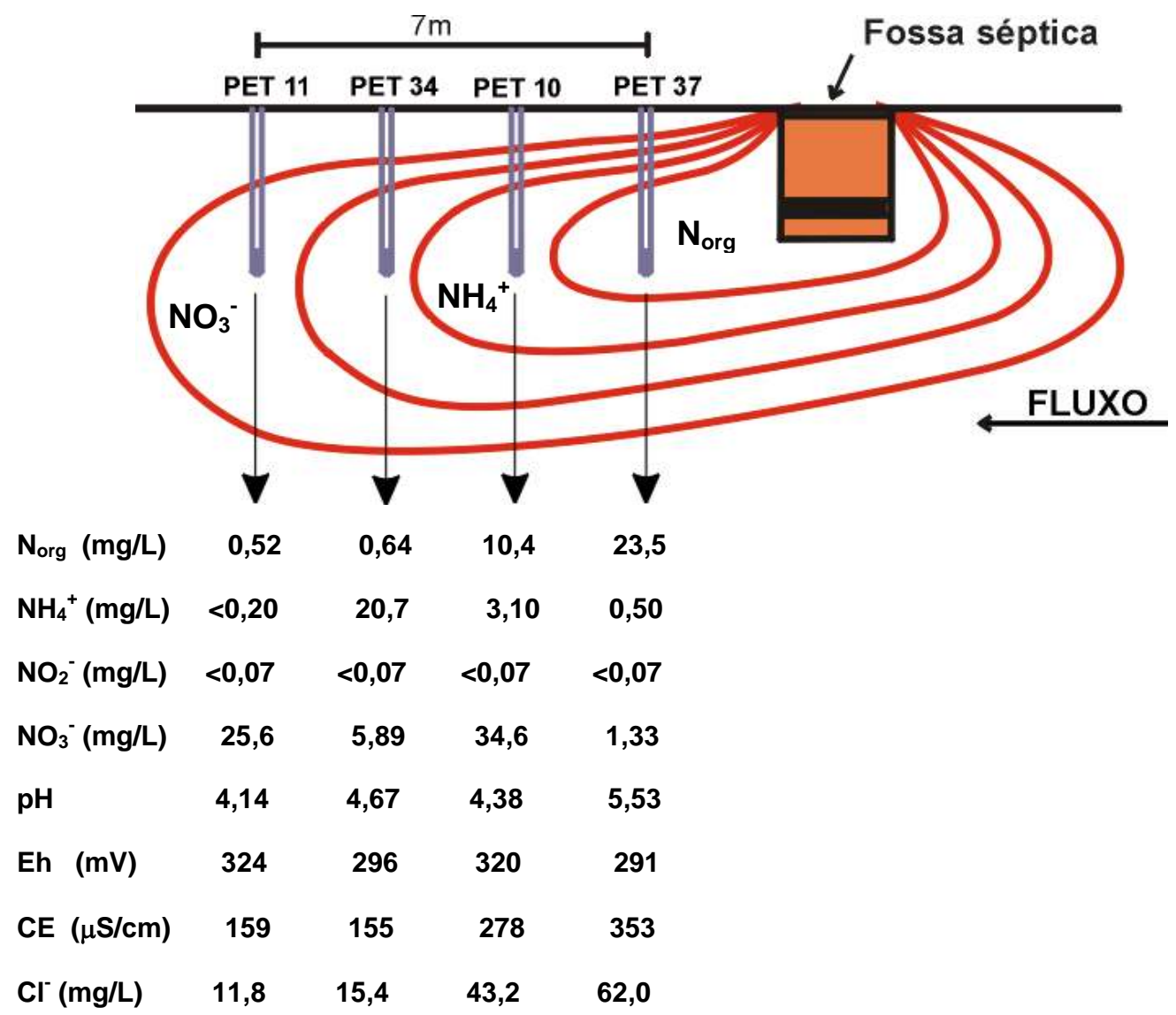

Figura 3 - Perfil esquemático ilustrando as zonas dos diferentes compostos nitrogenados na pluma.

A condutividade elétrica (CE) CONCLUSÕES apresentou uma boa relação com o Os resultados das análises físicocloreto. $\mathrm{O}$ aumento dos valores de CE químicas em amostras de água nos na água subterrânea reflete a poços de monitoramento instalados transferência dos constituintes da fossa indicaram contaminação por nitrato para o aqüífero. Assim como os demais proveniente do sistema de fossa séptica parâmetros, os valores de CE também com valores acima do limite permitido variaram com o tempo e espaço, por lei $\left(45 \mathrm{mg} / \mathrm{L} \quad \mathrm{NO}_{3}{ }^{-}\right)$. Todos os acompanhando a dinâmica de recarga e parâmetros analisados apresentaram chuvas. 
suas concentrações, em função dos efeitos da recarga e alteração no traçado dos tubos de fluxo.

Através dos resultados obtidos foi possível definir um zoneamento da série nitrogenada na pluma de contaminação, com predominância das formas reduzidas (nitrogênio orgânico e amônio) próximas ao sistema séptico e das formas oxidadas em locais mais distantes.
As rápidas variações das concentrações químicas de poluentes (menos de 15 dias) em um mesmo poço permitem concluir que um programa de monitoração em aqüíferos rasos e com rápida recarga deva ser conduzido com amostragens freqüentes, sob pena de não se detectar as reais concentrações da pluma contaminante.

\section{REFERÊNCIAS BIBLIOGRAFICAS}

American Public Health Association 1995. Standard methods for the examination of water and wastewater. $19^{\mathrm{a}}$ ed. Washington DC, American Water Works Association and Water Environment Federation. 1268p.

Foster, S. \& Gomes, D. 1989. Monitoreo de la calidad de las aguas subterráneas: una evaluación de métodos y costos. Lima, CEPIS-PAHO/WHO. 89p.

Instituto Brasileiro de Geografia e Estatística (1991) Censo demográfico do Brasil. URL http://www.ibge.gov.

Hirata, R.; Bastos, C.; Rocha, G. 1996. Mapa de vulnerabilidade das águas subterrâneas no Estado de São Paulo. São Paulo, Secretaria do Meio Ambiente de São Paulo. 95p.

Robertson, W.D.; Cherry, J.A.; Sudicky, E.A. 1991. Groundwater contamination from two small septic systems on sand aquifers. Groundwater 29 (1): 82-92.

Rudolph, D.; Kachanoski, G.; Wesenbeeck; I.; Barton, D.; Parkin, G.; Hirata, R.; Cey, E. 1997. Partitioning of solutes from agricultural fields within the hydrologic system at two sites in Southern Ontario and the subsequent impact on adjacent aquatic ecossystems. Final Report. University of Waterloo. Waterloo. 734p.

Wilhelm, S.; Schiff, S.; Cherry, J. 1994. Biogeochemical evolution of domestic waste in septic systems: 1. Conceptual Model. Groundwater 32 (6): 905-916.

United States Enviromental Protection Agency 2001. Test methods for evaluating solid waste, physical/chemical methods. URL http://www.epa.gov/epaoswer/hazwaste/ test/sw846

\section{AGRADECIMENTOS}

Os autores expressam os seus agradecimentos à FAPESP (Fundação de Amparo à Pesquisa do Estado de São Paulo) pela concessão do projeto de auxílio à pesquisa (processo 97/6950-6) e fornecimento de bolsa de Mestrado (processo 98/10481-4) bem como, aos funcionários do Parque Ecológico do Tietê ${ }_{2}$ do Laboratório CEIMIC e aos integrantes do Laboratório de Modelos Físicos do Instituto de Geociências da Universidade de São Paulo. 